\title{
Do Fences Reduce Fear of Crime
}

\section{Siti Rasidah Md Sakip, Norhafizah Abdul Rahman, Nadiyanti Mat Nayan}

\author{
Faculty of Architecture, Planning \& Surveying, \\ Universiti Teknolgi MARA Perak, 32610 Bandar Seri Iskandar, Perak, Malaysia \\ sitir704@perak.uitm.edu.my; norha776@perak.uitm.edu.my; nadiy028@perak.uitm.edu.my
}

\begin{abstract}
The Roadmap of Government Transformation Program 2010 reported that the sense of fear of crime among Malaysians is quite high which is 89 percent. So, the questions is, do they feel safe without fence? Therefore, this paper seeks on the neighborhood with no fence to identify the sense of safety and fear of crime (FOC) among residents. The result indicates that longer resident living in residential areas is significant with perceptions of crime (POC) in the neighborhood $(p=0.00)$. The more people go out at night is also significant with POC in the neighborhood $(p=0.012)$.

Keywords: Crime; quality of life; fear of crime; sense of safety

eISSN 2398-4279 @ 2018. The Authors. Published for AMER ABRA cE-Bs by e-International Publishing House, Ltd., UK. This is an open access article under the CC BY-NC-ND license (http://creativecommons.org/licenses/bync-nd/4.0/). Peer-review under responsibility of AMER (Association of Malaysian Environment-Behaviour Researchers), ABRA (Association of Behavioural Researchers on Asians) and cE-Bs (Centre for EnvironmentBehaviour Studies), Faculty of Architecture, Planning \& Surveying, Universiti Teknologi MARA, Malaysia.

DOI: https://doi.org/10.21834/ajqol.v3i10.97
\end{abstract}




\subsection{Introduction}

Urban population growth and development around the world have increased rapidly since the beginning of the Industrial Revolution (Merrick, 1989). Currently, Malaysia is experiencing rapid development in achieving the Vision of 2020. Therefore, Malaysia faces many challenges to be a development country such as escalating crime rates (Wong, 2006). In the Government Transformation Programme, the overall crime rate in Malaysia has increased from 746 reported crimes per 100,000 persons in 2006 to 767 in 2007 and 2008, a rise of nearly $3 \%$ (M. Hedayati Marzbali, 2011). Nowadays, the news distributed in the media has an impact on residents' perception of anxiety and feel less secure, especially when the crime of murder happened in residential areas. In spite of that, the sense of security is important for residents to ensure their families and their homes are safe from crime. If this could not happen, hence it will cause feelings of high anxiety and negative effects on individuals and communities (Merry, 1981). Scholars found that fear of crime has a relationship with housing residential (Merry, 1981; Siti Rasidah. M.S, 2013; Wilson-Doenges, 2000). The research highlights the importance of the physical environment in shaping perceptions of crime and safety. A Fence is one of the elements in physical structures can give the sense of security for residents. Thus, the gated communities are seen as a new concept of housing scheme and get a high demand of buyers. It is because the residents believed that the gated communities can give the sense of security for them. The scenario in Malaysia, the development of gated community residential concept entails two elements of a gate; at every individual lot and also around the perimeter of the residential area which coupled with a security guard post at the entrance to the residential area (Siti Rasidah. M.S, 2013). It means a gated community in Malaysia has a double gated: first gate in their compartment (lot area) and the second gate installed in the neighborhood area. However, there are also have a neighborhood without gate installed. So, the question is; is it resident feel safe without fence?. This research seeks to fill this gap. Therefore, the main objective of this paper is to examine the fear of crime among resident living in the neighborhood with no fence. The result of this study provides further insight into the way in which built environment shapes the sense of security.

\subsection{Literature Review}

The sense of fear of crime is defined as a feeling associated with emotional responses, feelings of fear and anxiety of something that is perceived to be detrimental or injury to a person (Pain, 2000; Ross \& Jang, 2000). This feeling can be explained as an expression of feeling or signal who feels in danger - related to crime (Lee, 2001; Pain, 2000; Stephen, Emily, \& Jonathan, 2007). Stephen et al., (2007) argued that sense of fears is one of the experiences related to the frequency of the crimes experiences that lead to high of feelings of anxiety or known as an emotional damage or malfunction. The causal factors of fear of crime are influenced by demographic background such as gender (Austin, Furr, \& Spine, 2002; Day, 2001; Hipp, 2010), age (Bannister \& Fyfe, 2001; Roh \& Oliver, 2005), socioeconomic (Joseph, 1997; Perkins, Wandersman, Rich, \& Taylor, 1993), education (Austin et 
al., 2002), the length occupied in residential area (Hipp, 2010) and ethnicity (Wilcox, Quisenberry, \& Jones, 2003).

The environmental factors also influence the fear of crime, namely the physical environment (Nasar \& Fisher, 1993; Perkins, Weeks, \& Taylor, 1992), social environment (Austin et al., 2002; O'Shea, 2006; Renauer, 2007) victimization (Lewis \& Salem, 1980; Reid, 2000; Wilcox et al., 2003) and possibility to be a crime victim. The physical environment can explain as any development on fixed elements based on the planning and physical design. The anxiety about the physical environment exists when the physical environmental disorder occur that leading to criminal behavior (Harang, 2003). According to Nasar \& Fisher (1993), victimization can be categorized into direct victimization and indirect victimization. Direct victimization is someone who has been a victim of actual crime. Meanwhile, indirect victimization is worried due to a person heard the news, issues, criminal cases from friends, relatives, neighbors and media (Banks, 2005; Ferguson \& Mindel, 2007).

In the theory of environmental criminology explained how the design and structure of physical space impedes surveillance and facilitates criminal of physical space impedes surveillance and facilitates criminal opportunities (Rollwagen, 2014). Based on Defensible Space theory by Newman (1972), discussed on how the residential space will defend against criminal activity by focusing on territoriality. Territoriality refers to real and symbolic barriers that elicit a sense of control and responsibility for a physical space (Newman, 1972). It refers to how people manage the spaces they own, how they occupy these spaces or use them at varying times. Although not purposely geared towards setting management, territorial functioning can contribute to the local ecology by playing a key role in the local territorial dynamic (Aldrin, 1999). In other words, strong territorial functioning prompts residents to exercise informal social control (Rollwagen, 2014). Therefore, this paper will find out and analyze of all the variables that affect the feelings of fear of crime against people who live in a residential area with not fenced. These findings can identify the presence of possible other factors that influence the feeling of fears'.

\subsection{Methodology}

\section{Case study: Putrajaya}

Putrajaya is the administrative center of the Malaysian federal government that replaced Kuala Lumpur in 1999. The name was given based on the first Prime Minister of Malaysia, Tunku Abdul Rahman Putra Al-Haj. The development of Putrajaya is based on the concept of a garden city with focusing on the provision of open space and recreation areas covering an approximately $39 \%$ of the total area in Putrajaya. Residents in Putrajaya in 2007 was 49,452 peoples (Putrajaya, 2009) concentrated on three main precinct; in Precinct 9 (44.60\%), Precinct $11(26.30 \%)$ and Precinct 8 (14.90\%). Bumiputeras (95.5\%) is dominated resident group in Putrajaya compared to another ethnicity $(4.50 \%)$ (Putrajaya, 2009). Residential area in the precinct 9 was chosen for this study because of the highest number of the population compared with another precinct. Also, the precinct 9 is also the earliest 
residential areas in Putrajaya (Putrajaya, 2009). The design of a residential area in Precinct 9 are designed without gated elements and equipped with modern facilities to meet the community's needs. This neighborhood involved of two-storey terrace houses without gated application. This concept of housing (without gated element) is the first applying in Malaysia (Roslan Talib, 2009).

Based on the crime statistics report for seven residential areas in Putrajaya (Precinct $8,9,10,11,14,16$ and 18) in the years 2005 to 2007, Precinct 9 has a highest criminal statistic of burglary (refer Table $1 \& 2$ ). It has to do with a high population in the neighborhood area. Specifically, burglary crimes in Precinct 9 have increased by 15 per case for five years (2005 to 2009). The daytime housebreaking is higher (89 cases) compared with the nighttime burglary (68 cases) as shown in Table 4.

Table 1: Daytime Burglary crime statistics at residential area in Putrajaya in 2005 to 2009 Types of crime Daytime of burglary

\begin{tabular}{llllllll}
\hline Year/ Residential & P8 & P9 & P10 & P11 & P14 & P16 & P18 \\
\hline 2005 & 4 & $\mathbf{9}$ & - & 1 & - & 4 & - \\
\hline 2006 & - & 16 & 1 & 7 & - & 2 & - \\
\hline 2007 & 1 & $\mathbf{9}$ & - & 8 & - & 8 & - \\
\hline 2008 & 3 & $\mathbf{2 8}$ & - & 10 & 3 & 1 & 5 \\
\hline 2009 & 2 & $\mathbf{2 7}$ & 1 & 5 & 3 & 7 & 5
\end{tabular}

Note: P8,P9,P10,P11,P14,P16,P18= Precinct 8, Precinct 9, Precinct 10, Precinct 11, Precinct 14, Precinct 16, Precinct 18

(Source: Royal Malaysia Police, Putrajaya branch)

Table 2: Night time Burglary crime statistics at residential area in Putrajaya in 2005 to 2009

\begin{tabular}{l|lllllll}
\hline Types of crime & \multicolumn{7}{|l}{ Night time of burglary } \\
\hline Year/ Residential & P8 & P9 & P10 & P11 & P14 & P16 & P18 \\
\hline 2005 & 6 & $\mathbf{1 9}$ & 1 & 17 & 3 & 1 & - \\
\hline 2006 & - & $\mathbf{5}$ & 5 & 5 & - & 2 & - \\
\hline 2007 & - & $\mathbf{1 3}$ & - & 1 & - & 1 & - \\
\hline 2008 & 2 & $\mathbf{1 5}$ & 1 & 11 & 2 & - & - \\
\hline 2009 & 2 & $\mathbf{1 6}$ & - & 10 & 3 & 1 & 1
\end{tabular}

Note: P8,P9,P10,P11,P14,P16,P18= Precinct 8, Precinct 9, Precinct 10, Precinct 11, Precinct 14, Precinct 16, Precinct 18

(Source: Source: Royal Malaysia Police, Putrajaya branch)

Table 3: Burglary crime statistics in Precint 9 in 2005 to 2009

\begin{tabular}{llllll}
\hline Types of crime & 2005 & 2006 & 2007 & 2008 & 2009 \\
\hline Daytime of burglary & 9 & 16 & 9 & 28 & 27 \\
Nightime of burglary & 19 & 5 & 13 & 15 & 16 \\
\hline Total & 28 & 21 & 22 & 43 & 43 \\
\hline
\end{tabular}

(Source: Source: Royal Malaysia Police, Putrajaya branch)

The research method included a structured questionnaire, which was administered in the context of face-to-face structured and formal interviews. The settings of the interviews were the preselected residential areas in Precinct 9 in Putrajaya. The focus of this study involves 
groups of residents earning a medium high level of income between RM3000 to RM5000 and are categorized as able to afford medium-high cost houses (JPBD, 2009; Putrajaya, 2009). The study employs the population survey approach on individual non-gated residential areas in Putrajaya. The neighborhood area in Precinct 9 is selected for the case study because of the highest population in the area compared to another precinct (Putrajaya, 2009). This neighborhood involved 201 households. The respondents comprised of heads of households or the main bread earners in the household. Hence, either the husband or the wife was selected as respondent on account of their responsibility towards the residence. In the event both parties agreed to be the respondents, only one will be randomly selected. Before commencing questionnaire and observatory studies, a preliminary site study was conducted to identify unoccupied residences such as neighborhood watch beats, kindergartens, child care centers, storage buildings and vacant residences. Out of 275 residences, 11 have been eliminated from the respondent selection list as they have been identified as having a nonresidential use. On the whole, this population study involved a total of 264 residences and the response rate is $31 \%$.

\section{Measuring the fear of crime}

The fear of crime (FOC) construct is based on four dimensions; (a) physical environment (PHE), (b) social environment (SOE), (c) indirect victimization (INV) and (d) possibility to be a crime victim (PCV). All these dimensions were measured using questionnaire items adapted from past questionnaire studies by Banks (2005), British Crime Survey (2005), Ferguson and Mindel (2007), Nasar and Fisher (1993), O'Shea (2006) as well as Perkins, Weeks and Taylor (1992). Every item or statement in this questionnaire will be followed by eight choices of answers using the Likert Scale. Choices of response range from (1) Highly Disagree to (8) Highly Agree for the PHE, SOE, INV and PCV dimensions. A high score indicates that the respondent has a high degree of fear of crime and conversely a mean score indicates a low fear of crime.

The validation and confirmation of all constructs were done using Exploratory Factor Analysis (EFA). EFA is used to gather information about the interrelationship among a set of variables (Pallant, 2005). The result for the level of reliability was found by calculating the Cronbach's Alpha. The dimensions of the construct have a good reliability value as the Cronbach's Alpha value exceeds 0.60 (Nunnally \& Bernstein, 1994). The results indicated that the Alpha values for fear of crime (FOC) dimensions were the physical environment $(\mathrm{PHE})=.95$, social environment $(\mathrm{SOE})=.96$, indirect victimization $(\mathrm{INV})=.93$ and possibility to be a crime victim $(P C V)=.88$. The Cronbach's Alpha value for a perception of crime in the neighborhood (POC) construct was .89. These results of Alpha value for all construct and dimensions achieved good Alpha reliability levels (Nunnally \& Bernstein, 1994).

\subsection{Findings and Discussions}

Respondent involved in this research is $65.4 \%$ female and $34.6 \%$ male. They were $46.9 \%$ aged in the 40 s followed by the 30 s (37\%), 50 s (8.6\%) and 20 s (7.4\%). $43.2 \%$ of respondent have stayed in the residential area for 3 to 4 years, followed by 5 to 6 years $(25.9 \%)$ and 1 to 
2 years $(22.2 \%)$. Most of the respondents are renters (86.4\%), married $(90.1 \%)$ and had higher education up to university level $(84 \%)$. Most of them work in private companies $(66.7 \%)$, and only $24.7 \%$ are employed in the government sector, and the rest worked in the private sector $(4.9 \%)$ and retirees $(3.7 \%)$.

The other objective of this paper is to seek the sense of fear of crime among residents. Table 4 shows the result of the perception of crime in the neighborhood (POC). This construct used to identify the problems of crime in the neighborhood area. There are five items in POC, and the finding shows that vandalism is the most problematic in the neighborhood $(M=2.55, S D=1.38)$, followed by house breaks-in $(M=2.06, S D=1.26)$. This finding indicates that respondents are more worried on vandalism and burglary in their neighborhood. It has relation with crime statistic in the neighborhood (refer Table 2) which states that the burglary in the neighborhood is increased. This result is in line with items in the variable of possibility to be a crime victim (PCV) which found that the respondent is more worried about the possibility their home was broken into $(M=3.43, S D=1.50)$ as shown in Table 5. A concern of vandalism is possibility has to do with the environmental in the neighborhood as mentioned by Rollwagen. $\mathrm{H}$ (2014). He stated that the built environment played a role in shaping individual experiences and perception of crime.

Table 4: Burglary crime statistics in Precint 9 in 2005 to 2009

\begin{tabular}{lcc}
\hline Items & Mean & SD \\
\hline Occurrences of house breaks-in or theft & $\mathbf{2 . 0 6}$ & $\mathbf{1 . 2 6}$ \\
Theft of vehicles (cars, motorcycles, vans, bicycles, lorries and others) & 1.81 & 1.05 \\
Vandalism problems such as breaking windows and destruction of public property & & \\
Problems regarding the selling and buying of drugs & $\mathbf{2 . 5 5}$ & $\mathbf{1 . 3 8}$ \\
Physical attack on individuals such as assault & 1.72 & 1.01 \\
& 1.66 & 0.83 \\
\hline
\end{tabular}

Table 5: Correlation between perception on crime in neighborhood, possibility to be a crime victim, physical environment, social environment and indirect victimization

\begin{tabular}{|c|c|c|c|c|c|}
\hline \multicolumn{2}{|c|}{ Variables } & 1 & 2 & 3 & 4 \\
\hline (1) & $\begin{array}{l}\text { Perception on crime in } \\
\text { neighborhood (POC) }\end{array}$ & & & & \\
\hline (2) & Possibility to be a crime & $.555^{*}$ & & & \\
\hline & victim (PCV) & $.520^{* *}$ & .227 & & \\
\hline (3) & $\begin{array}{l}\text { Physical environment } \\
\text { (PHE) }\end{array}$ & & & & \\
\hline (4) & $\begin{array}{l}\text { Social environment } \\
\text { (SOE) }\end{array}$ & $.497^{* *}$ & .126 & $.912^{*+*}$ & \\
\hline (5) & $\begin{array}{l}\text { Indirect victimization } \\
\text { (INV) }\end{array}$ & $.518^{* *}$ & .183 & $.864^{* *}$ & $.877^{\star \star}$ \\
\hline
\end{tabular}


The fear of crime (FOC) construct includes four dimensions that are the physical environment (PHE), social environment (SOE), indirect victimization (INV) and possibility to be a crime victim (PCV). In PHE, mostly residents have a sense of fear towards abandoned housing $(M=3.97, S D=1.86)$ and worried when came across with people in intoxicated on $\operatorname{SOE}(M=4.02, S D=1.98)$, fears when hearing someone in crime victims from their neighbors or friends on INV $(M=4.14, S D=1.59)$ and worried if possibility their homes breaks into on $\operatorname{PCV}(M=3.43, S D=1.50)$. This result found that hearing crime news from television, radio or any electronic media, newspaper, friends or neighbors give the sense of fear of (Grabosky, 1995). This result is consistent with Killias (1990), argued that they will imagine the criminal acts depicted from the newspapers, news, friends, etc. that cause a worry if it happens to them.

T-test analysis was conducted to identify the FOC on homeowners for PHE, SOE, INV, PCV, and POC. The result shows there is a significant difference between PHE on the homeowner $(t(79)=2.94 ; p=0.00)$ but not significant with other variables $(\mathrm{SOE}, \mathrm{INV}, \mathrm{PCV}$, $\mathrm{POC}$ ). In spite, that, gender is not a significant difference in any dimension on FOC. This result explained the respondents are more worried towards the physical environment. Possibility it has associated with a neighborhood setting such as an isolated area, bushes and any vandalism (Rollwagen. $\mathrm{H}, 2014$ ).

Table 6: ANOVA analysis between physical environment, social environment, indirect victimization and possibility to be a crime victim on group of age

\begin{tabular}{|c|c|c|c|c|c|c|}
\hline & & Sum of Squares & df & Mean Square & $F$ & Sig. \\
\hline \multirow[t]{3}{*}{$\overline{P O C}$} & Between Groups & 187.695 & 3 & 62.565 & 3.026 & .035 \\
\hline & Within Groups & 1591.885 & 77 & 20.674 & & \\
\hline & Total & 1779.580 & 80 & & & \\
\hline & Between Groups & 770.790 & 3 & 256.930 & 15.179 & .000 \\
\hline \multirow{2}{*}{ PHE } & Within Groups & 1303.383 & 77 & 16.927 & & \\
\hline & Total & 2074.173 & 80 & & & \\
\hline \multirow{3}{*}{ SOE } & Between Groups & 689.796 & 3 & 229.932 & 10.901 & .000 \\
\hline & Within Groups & 1624.155 & 77 & 21.093 & & \\
\hline & Total & 2313.951 & 80 & & & \\
\hline \multirow{3}{*}{ INV } & Between Groups & 499.204 & 3 & 166.401 & 13.227 & .000 \\
\hline & Within Groups & 968.673 & 77 & 12.580 & & \\
\hline & Total & 1467.877 & 80 & & & \\
\hline \multirow{3}{*}{ PCV } & Between Groups & 50.371 & 2 & 25.185 & .876 & .439 \\
\hline & Within Groups & 373.567 & 13 & 28.736 & & \\
\hline & Total & 423.938 & 15 & & & \\
\hline
\end{tabular}

Note: $\mathrm{PHE}=$ physical environment, $\mathrm{SOE}=$ social environment, INV= indirect victimization, $\mathrm{PCV}=$ possibility to be a crime victim, $\mathrm{POC}=$ perception on crime in neighborhood

The correlation between the variable in fear of crime was analyzed to identify the significant correlation between variables. The output in Table 5 shows that the relationship between perception of crime in the neighborhood (as measured by POC), possibility to be a crime victim (PCV), physical environment (PHE), social environment (SOE), and indirect victimization (INV) and was investigated using Pearson product-moment correlation coefficient. There was a strong, positive correlation between PCV with POC $(r=.55, n=81$, 
$p<.0005)$, PHE with POC ( $r=.52, n=81, p<.0005)$, SOE with POC $(r=.49, n=81, p<.0005)$, SOE with PHE $(r=.91, \mathrm{n}=81, p<.0005)$, INV with POC $(r=.51, \mathrm{n}=81, p<.0005)$, INV with PHE $(r=. .86, n=81, p<.0005)$ and INV with SOE $(r=.877, n=81, p<.0005)$.

Next, this study also identifies the correlation between age groups within the variables of fear of crime. A one-way between-groups analysis of variance was conducted to explore the impact of age on POC, PHE, SOE, INV, and PCV. Subjects were divided into four groups according to their age (Group 1:20s; Group 2: 30s, Group 3: 40s and Group 4: 50 s and above). There was a statistically significant difference at the $p<.05$ level for the POC for the four age group $[F(3,77)=3.026, p=.03]$, PHE with the age group $[F(3,77)=15.17, p=.00]$, SOE with the age group $[F(3,77)=10.9, p=.00]$, and INV with the age group $[F(3,77)=$ $13.22, p=.00]$. However, there are not significantly within PCV with the age group $[F(2,13)$ $=.876, p=.43]$. Despite reaching statistical significance, the actual difference in mean score between the groups was quite small. The effect size, calculated using eta squared was PHE= $0.3, \mathrm{SOE}=0.2$, and INV=0.3. The result is shown in Table 6 .

\subsection{Conclusion}

The main goal of this paper is to identify the sense of fear of crime among resident in the neighborhood with no gated/fence. This research found that the residents in Precinct 9 Putrajaya do have a sense of fear of crime, but it's specific to the physical environment. This finding approved that the environmental setting is important elements as factors of the feeling of security. However, social cohesion in a neighborhood is influenced by the sense of fear of crime. This is an important element that needs to investigate in the future research of this study. In spite, this study has shown that physical and social environment, the perception of crime in the neighborhood, indirect victimization and the possibility to be a crime victim had a positive and highly interrelated to each other. Instead also ages significantly to the feelings of anxiety about crime.

\section{References}

Aldrin, A. (1999). Crime Landscape: The Relationship of Victimisation and Fear of Crime With Residents' Territorial Functioning in High and Low Crime Rate Estate in Sheffield University of Sheffield, U.K.

Austin, D. M., Furr, L. A., \& Spine, M. (2002). The Effects of Neighborhood Conditions on Perception of Safety. Journal of Criminal Justice, 30, 417-427.

Banks, M. (2005). Spaces of (in) Security: Media and Fear of Crime in a Local Context. Crime, Media, Culture, 1(2), 169-187.

Bannister, J., \& Fyfe, N. (2001). Introduction: Fear and the City. Urban Studies, 38(5-6), 807-813.

Day, K. (2001). Fear of Crime and The Physical Environment. In A. Z. D. Brennan (Ed.), Safescape: Creating Safer, More Liveable Communities Through Planning \& Design. United States America: American Planning Association. 
Ferguson, K. M., \& Mindel, C. H. (2007). Modeling Fear of Crime in Dallas Neighborhoods: A Test of Social Capital Theory. Crime \& Delinquency, 53(2), 322-349.

Grabosky, P. N. (1995). Fear of Crime and Fear Reduction Strategies. Australian Institute of Criminology.

Harang, M. (2003). The Improvement of the Quality of Life in Residential Areas: The Policy Treeo. Document Number)

Hipp, J. R. (2010). Resident Perceptions of Crime and Disorder: How Much is "Bias", and How Much is Sosial Environment Differences? American Society of Criminology, 48(2), 475-508.

Joseph, J. (1997). Fear of Crime Among Black Elderly. Journal of Black Studies, 27(5), 698-717.

JPBD. (2009). Draf Akhir Laporan Teknikal 'Gated and Guarded Community'. Kuala Lumpur: MN Consulto. Document Number)

Lee, M. (2001). The Genesis of 'Fear of Crime'. Theoretical Criminology, 5, 467-485.

Lewis, D. A., \& Salem, G. (1980). Community Crime Prevention: An Analysis of A Developing Strategy.Unpublished manuscript, North-western University.

M. Hedayati Marzbali, A. A., N.A. Razak \& M.J. Maghsoodi Tilaki. (2011). Using Hotspot Mapping to Understand Spatial Patterns of Burglary in Residential Land Use: A Case Study of Penang. World Applied Sciences Journal, 13(8), 1948-1958.

Merrick, T. (1989). World population in transition Population Bulletin, 41.

Merry, S. E. (1981). Urban danger: Life in a neighborhood of strangers. Philadelphia: PA: Temple University Press.

Nasar, \& Fisher, B. (1993). 'Hot Spots' of Fear and Crime: A Multi-Method Investigation. Journal of Environmental Psychology, 13, 187-206.

Newman, O. (1972). Crime Prevention Through Urban Design Defensible Space. New York: The Macmillan Company.

Nunnally, J. C., \& Bernstein, I. H. (1994). Psychometric Theory. New York: McGraw-Hill.

O'Shea, T. C. (2006). Physical Deterioration, Disorder, and Crime. Criminal Justice Policy Review, 17(2), 173-187.

Pain, R. (2000). Place, social relations and the fear of crime: A review. . Progress in human geography, 24(3), 365387.

Pallant, J. (2005). SPSS Survival Manual; A Step by Step Guide to Data Analysis Using SPSS for Windows. Sydney, Australia: Allen \& Unwin.

Perkins, Wandersman, A., Rich, R. C., \& Taylor, R. B. (1993). The Physical Environment of Street Crime: Defensible Space, Territoriality and Incivilities. Journal of Environmental Psychology, 13(1).

Perkins, Weeks, J. W., \& Taylor, R. B. (1992). The Physical Environment of Street Blocks and Resident Perceptions of Crime and Disorder: Implicatons for Theory and Measurement. Journal of Environmental Psychology, 12(1), 2134. 
Putrajaya, P. (2009). Laporan Pemeriksaan; Draf Rancangan Struktur Putrajaya. Putrajaya: Perbadanan Putrajayao. Document Number)

Reid, S. T. (2000). Crime and Criminology (Ninth ed.). U.S: McGraw-Hill Higher Education.

Renauer, B. C. (2007). Reducing Fear of Crime: Ctizen, Police or Government Responsibility? Journal Police Quarterly, 10(1), 41-62.

Roh, S., \& Oliver, W. M. (2005). Effects of Community Policing Upon Fear of Crime Understanding The Causal Linkage. An International Journal Police Strategies \& Management, 28(4), 670-683.

Rollwagen, H. (2014). The Relationship Between Dwelling Type and Fear of Crime. Environment and Behavior, 123.

Ross, C. E., \& Jang, S. J. (2000). Neighborhood Disorder, Fear, and Mistrust: The Buffering Role of Social Ties with Neighbors. American Journal of Community Psychology, 28(4), 401-420.

Stephen, F., Emily, G., \& Jonathan, J. (2007). Theorising the Fear of Crime: The Cultural and Social Significance of Insecurities about Crime. Institute of Law, Politics and Justice, Keele University, Staffordshire, England, \& Methodology Institute, London School of Economics, Houghton Street, London.

Welsh, B. C., \& Hoshi, A. (2002). Communities and Crime Prevention. In Evidence-Based Crime Prevention. New York: Routledge.

Wilcox, P., Quisenberry, N., \& Jones, S. (2003). The Build Environment and Community Crime Risk Interpretation. Journal of Research in Crime and Delinquency, 40(3), 322-345.

Wilson-Doenges, G. (2000). An exploration of sense of community and fear of crime in gated communities. Environment and Behavior, 32(597-611).

Wong, T. C., B.J.Shaw and K.C.Goh. (2006). Challenging sustainability: Urabn development and change in Southeast Asia (2nd Edition ed.). California: Marshall Cavendish Academic. 